\title{
La vida como una posibilidad limitada. El problema de la libertad en José Ortega y Gasset* $^{*}$
}

\author{
Life as a limited possibility. \\ The problem of liberty in José Ortega y Gasset
}

\author{
DOROTA LESZCZYNA \\ Universidad de Wroclaw
}

Recibido: 23/03/2020 Aceptado:25/09/2020

\section{RESUMEN}

El objetivo del artículo es presentar el problema de la libertad según José Ortega y Gasset, en su proyecto de superar el idealismo, el realismo y la ontología tradicional, fundada esta última en un concepto estático y sustancial del «ser». El filósofo español sustituyó este eleatismo ontológico por un concepto de «ser» entendido como una relación dinámica entre el yo y su circunstancia, y donde la libertad individual sólo se puede salvar. La libertad real, no la abstracta o la hipotética, implica un ser privado de esencia, un ser plástico, dotado de imaginación, que le permite proyectarse a sí mismo de manera libre, aunque no de cualquier manera, dado que estamos inscritos en el horizonte de nuestra circunstancia. Por ello, para Ortega, la vida es una posibilidad limitada, un drama que se realiza entre lo que queremos ser y lo que tenemos que ser.

\author{
PALABRAS CLAVE \\ LIBERTAD, ORTEGA, SER, VIDA, REALIDAD RADICAL, CATEGORÍAS DE LA \\ VIDA, NECESIDAD, FATALIDAD
}

* Este trabajo se enmarca en el siguiente proyecto de investigación: Poza idealizmem i realizmem: filozofia Nicolaia Hartmanna i José Ortegi y Gasseta; Narodowe Centrum Nauki, nr rej. 2017/27/B/HS1/00562.

(C) Contrastes. Revista Internacional de Filosofía, vol. XXVI N ${ }^{\circ} 1$ (2021), pp. 27-41. ISSN: 1136-4076

Departamento de Filosofía, Universidad de Málaga, Facultad de Filosofía y Letras Campus de Teatinos, E-29071 Málaga (España) 


\section{ABSTRACT}

The objective of this article is to present the problem of freedom according to José Ortega y Gasset. It should be noted that this problem is part of the Orteguian project of overcoming idealism and realism, as well as traditional ontology. This ontology was based on a static and substantial concept of being. The Spanish philosopher replaced this ontological eleatism with a concept of «being» understood as a dynamic relationship between the self and its circumstance. In his opinion, only within the framework of such a relationship can we justify and save individual freedom. In Ortega, real freedom, not abstract or hypothetical, therefore implies a being deprived of essence, a plastic being, endowed with imagination, which allows us to project ourselves freely, but not in any way. We cannot shape our life in any way, because we are inscribed on the horizon of our circumstance. That is why for the Spanish philosopher the life of the individual is a limited possibility, it is a drama that takes place between what we want to be and what we have to be.

KEYWORDS

LIBERTY, ORTEGA, BEING, LIFE, RADICAL REALITY, CATEGORIES OF LIFE, NECESSITY, FATALITY

\section{INTRODUCCIÓN}

EN OPINIÓN DEL PENSADOR alemán Nicolai Hartmann, profesor de la escuela neokantiana de Marburgo, sobre la unidad y el progreso de la filosofía deciden la unidad y el progreso de los problemas filosóficos que surgen a lo largo de la historia y son abordados una y otra vez. Estos problemas tienen una continuidad histórica, pero no en el sentido de que cada pensador abordaba cada problema, o todos ellos existían desde el principio, sino porque el problema una vez descubierto va más lejos - a través de toda una serie de intentos de resolverlo - a saber, hasta que no sea realmente resuelto ${ }^{1}$. Y como los problemas filosóficos son de hecho inescrutables, precisamente ellos conectan intrínsecamente el pensamiento de mentes muy diferentes y épocas enteras ${ }^{2}$.

Uno de esos problemas que conectan tanto mentes como épocas es sin duda el problema de la libertad, cuyos inicios se remontan a la Grecia antigua, y que acompaña al hombre hasta día de hoy, despertando en él exactamente

1 N. Hartmann, «Der philosophische Gedanke und seine Geschichte», en Abhandlungen der Preußischen Akademie der Wißenschaften, Philosophisch-Historische Klaße, 1936. Este texto fue publicado en N. Hartmann, Kleinere Schriften II. Abhandlungen zur Philosophie-Geschicht. Berlín: De Gruyter, 1957, pp. 1-48. Existe también la traducción castellana de este trabajo: El pensamiento filosófico y su historia, traducción y estudio sobre «Gnoseología de Hartmann» y «El método crítico» de Aníbal del Campo. Montevideo: Claudio García \& Cia. Editores, 1944.

2 Ibídem. 
el mismo sentimiento de intranquilidad e insaciabilidad cognitiva que hace más de dos mil años. Por supuesto, el problema de la libertad, como cualquier otro, estaba y está sujeto a diferentes cambios que determinan normalmente factores externos y extrafilosóficos. Se trata, ante todo, del contexto histórico y circunstancial en el que surge y los diversos modos de abordarlo. Junto con el desarrollo histórico aparecen nuevos aspectos, partes y perspectivas para presentar el problema de la libertad, relacionados con la adquisición de experiencia por el hombre y los intentos de evitar los errores cometidos por los predecesores. Esto también incluye la historicidad de la filosofía, puesto que, como escribía Hartmann:

no comienza por sí misma, sino aprovecha los conocimientos reunidos durante siglos y la experiencia metódica de todas las ciencias, así como de la experiencia de doble filo de los sistemas filosóficos. Aprende de todo. Lo único que debería evitar son las premisas especulativas y constructivas que preceden a los estudios y determinan de antemano sus objetivos ${ }^{3}$.

En este artículo deseo abordar el problema de la libertad en el ámbito de la filosofía de José Ortega y Gasset ${ }^{4}$. También en este caso nos enfrentamos a un intento de superar la interpretación presentada por sus predecesores y sacar conclusiones de los errores cometidos por ellos. Sin embargo, debemos subrayar la importancia que concedía el filósofo madrileño al concepto de «superación» ${ }^{5}$. No significa, como podría parecer inicialmente, una ruptura o un rechazo del pasado, sino su negación y conservación simultánea. Usando la terminología hegeliana, podríamos decir que se trata aquí de la llamada negación determinada, aunque Ortega, al contrario que Hegel, la basa no en los principios de la razón absoluta y lógica, sino en los principios de la razón vital e histórica ${ }^{6}$. En Ortega, la superación significa una especie de acumulación del pasado, su absorción e incorporación, que es imprescindible para llegar a un

3 N. Hartmann, Der Aufbau der realen Welt. Grundriss der allgemeinen Kategorienlehre. Aufl. 3. Berlín: De Gruyter, 1964, s. X.

4 Gutiérrez Simón, Rodolfo, «Los límites del sujeto y la libertad en Ortega y Gasset», Daimon, 69, (2016), pp. 109-123.

5 Según José González Sandoval Buedo: «El término “superación” puede ser entendido de dos maneras diferentes: Por un lado, se puede interpretar en sentido nietzscheano "transcender", proceso en el cual lo superado queda relegado y, de alguna manera negado, destruido y desplazado en su integridad por otra "entidad" diferente que la sustituye. Por otro, se puede entender "superación", según el sentido de la Aufhebung de la dialéctica hegeliana, como un proceso mediante el cual lo superado no es negado en su totalidad, sino parcialmente conservado». José González Sandoval Buedo, «El concepto de «superación» en Ortega», Contrastes, 6, (2001), p. 183.

6 Ortega traduce el verbo alemán Aufheben utilizando los verbos españoles: absorber resumir, sumir en y resolverse en. También lo traduce, remitiéndose a las obras sobre Hegel de Benedetto Croce, como superar. Véase J. Ortega y Gasset, Hegel. Notas de trabajo. (Eds.) D. Hernández Sánchez, Madrid: Abada, 2007, p. 31. 
nivel de filosofía nuevo y superior que demuestre su progreso histórico. «Este progreso - establece el filósofo madrileño - exige que esta nueva forma supere la anterior, y para superarla la conserve y aproveche; que se apoye en ella, que se suba sobre sus hombros, como una temperatura más alta va a caballo sobre las otras más bajas. Progresar es acumular ser, tesaurizar realidad» ${ }^{7}$.

Asimismo, debemos señalar que la interpretación del problema de la libertad en Ortega es una de las muchas ejemplificaciones de su proyecto de liberación del realismo y el idealismo, el racionalismo y el vitalismo, el determinismo y el indeterminismo y otros «ismos» que tienen carácter excluyente, y por eso abstracto e hipotético, y constituir en su lugar una nueva filosofía, una filosofía "sobrepartidista», real e integradora, es decir, que estuviera libre de la elección dogmática de cualquiera de las partes ${ }^{8}$. En este sentido, este problema está estrechamente vinculado con toda su filosofía, que él mismo definía como filosofía raciovital o filosofía de la razón vital e histórica.

\section{DifICULTADES RELACIONADAS CON LA PRESENTACIÓN DEL PROBLEMA DE LA LIBERTAD EN LA FILOSOFÍA DE ORTEGA Y GASSET}

La presentación de la interpretación orteguiana del problema de la libertad no es una tarea nada fácil. Esto se debe principalmente al carácter relacional de la filosofía del pensador madrileño, en la que cada elemento, problema, cuestión aparece en un número infinito de relaciones con los otros, constituyendo apenas una parte de una totalidad mayor ${ }^{9}$. Además, esta totalidad no tiene en Ortega una naturaleza duradera y estática, sino es algo que sucede, ocurre, se realiza. Constituye una especie de fieri que es la negación de la interpretación eleática del ser estable e inmóvil. Ortega llamó esta totalidad una «realidad radical», con lo que quería decir que es el inicio, la base y el fin de todo, porque todo lo que es, todo lo que sucede, proviene de ella, existe en relación a ella y para ella, y aspira a ella. Esta realidad la constituye a su vez la vida humana, entendida como individual, concreta e intransferible, como vida

7 J. Ortega y Gasset, «Historia como sistema y del Imperio Romano», VI, p. 74. En este trabajo las citas de las obras de Ortega remiten a la nueva edición de Obras completas t. I-X, (eds.) Fundación José Ortega y Gasset/Centro de Estudios Orteguianos, Madrid: Fundación José Ortega y Gasset \& Taurus, 2004-2010. Al título del texto sigue en números romanos el tomo y en arábigos la página.

8 Sobre este tema véase D. Leszczyna, Del idealismo al realismo crítico. La política como realización en José Ortega y Gasset. Berlín, Bern, Bruxelles, New York, Oxford, Warszawa, Wien: Peter Lang, 2020, pp. 218.

9 Sobre la idea del pensamiento complejo en Ortega véase María Isabel Ferreiro Lavedán, «Ortega y Gasset, iniciador del pensamiento complejo», Revista de Estudios Orteguianos, 4, (2002), pp.137-154 
de un individuo en el marco de la cual se efectúa y se realiza la coexistencia de «mi yo» y la circunstancia.

La vida es —nada menos - la realidad primordial en que todas las demás se fundan y a la que, en uno u otro sentido, habrá que reducir todas las otras si se quiere conocer su esencia radical. Porque en la vida solo hay ingredientes vitales: todo, pues, lo que en ella surja, entre, aparezca o se halle tendrá primariamente un carácter sustantivo vital, será «vida». Todo: yo no soy sino vida, mi vida; esta mesa es mi vida, y esa luz y ustedes son vida mía, y Dios no es — por lo prontosino algo vital mío ${ }^{10}$.

El problema de la libertad exige en Ortega el arraigo en la realidad radical de la vida de la que emerge. Es un problema propio de esta realidad; es un problema inmanente del individuo vivo, que cuenta con el mundo que le rodea, se preocupa y mide con él. Esto a su vez hace que, antes de pasar al concepto de libertad, debamos presentar los principales aspectos de la propia vida, llamados por Ortega categorías. Así, la libertad resulta ser una de esas categorías donde por categorías no entendemos ni las generalizaciones inductivas al estilo de Aristóteles, ni los puros y originarios conceptos a priori derivados deductivamente del intelecto puro, como sucedía en Kant, sino una especie de componentes preintelectuales que constituyen la estructura real de la vida, que solo podemos exponer, pero que es imposible agotar intelectualmente ${ }^{11}$.

10 J. Ortega y Gasset, «¿Qué es la vida? Lecciones del curso 1930-1931», VIII, pp. 419-420.

11 La idea de buscar y exponer los ingredientes de la vida, es decir, las categorías procede de Wilhelm Dilthey, cuyas obras Ortega empezó a estudiar de forma sistemática a los finales de los años veinte. Muy interesante es la investigación acerca de este tema realizada por Nelson R. Orringer. Según Orringer, Ortega entró en la filosofía de Dilthey, estudiando las obras del filósofo aleman - Georg Misch. Como leemos en su artículo recien publicado: «Al redactar estas palabras, que minimizaban el impacto de Wilhelm Dilthey en él, Ortega se sentía como quien llega a la estación turbado, deseando ser pasajero, pero viendo el tren alejarse de la plataforma. Su coetáneo Heidegger había descubierto la relevancia de Dilthey para la nueva época, y Ortega tuvo que alcanzarle dominando cuanto antes el pensamiento de Dilthey. Por eso, Ortega se apresuró a leer dos estudios extensos de Georg Misch, autor elogiado por Heidegger en El ser y el tiempo como indispensable para aprender las tendencias centrales de Dilthey (Heidegger 1977, $\S 77$, p. 399, nota 3).1 Misch (1875-1965), yerno de Dilthey, había sido además su discípulo más próximo (Ortega 2006, p. 229). Sostenemos que, para comprender a Ortega y su tratamiento de Dilthey en torno a 1929, es menester leer al filósofo berlinés como le veía Misch, escritor más vibranterítmico y plástico que su maestro». N. R. Orringer, «Reforma de la filosofía de Ortega y la nueva filosofía de la vida de Dilthey según Misch», Disputatio, 11, (2019), p. 116-117. 


\section{LA LIBERTAD Y OTRAS CATEGORÍAS DE VIDA}

Las categorías entendidas como ingredientes originarios y preintelectuales de la realidad radical tienen en Ortega un doble aspecto. Son a la vez individuales y universales. Su individualidad consiste en que la vida que determinan es siempre concreta, única e irrepetible, es «mi vida», que nadie puede vivir por mí y cuya experiencia no puedo transmitir a nadie. Al mismo tiempo, en base a la analogía con respecto a «mi vida», en la que me encuentro no solo a mí mismo, sino también el mundo, y en él a otras personas y sus productos, puedo intentar distinguir en ella ciertos rasgos que la conectan con la «vida de otro», la «vida ajena» y, por lo tanto, rasgos comunes y universales a toda vida. La indicación del doble aspecto de la realidad radical de la vida no plantea, según el filósofo madrileño, ninguna contradicción. La contradicción surge solo cuando examinamos la vida desde la perspectiva tradicional del ser, en la que la vida es algo dado e invariable ${ }^{12}$. Sin embargo, la vida no tiene nada que ver con el eleatismo, ya que es un suceder absoluto, puro e inevitable del hombre y el mundo para sí mismo. Así, como establece Ortega:

Como nuestra realidad «vivir» es muy distinta de la realidad cósmica antigua estará constituida por un conjunto de categorías o componentes todos ellos forzosos, igualmente originarios e inseparables entre sí. Estas categorías de «nuestra vida» buscamos - «nuestra vida» es la de cada cual, por tanto, distinta la mía de la tuya, pero ambas son «mi vivir» y en ambas habrá una serie de ingredientes comunes - las categorías de «mi vida» ${ }^{13}$.

Ortega, al hacer un análisis de la realidad radical de la vida, reveló en su marco dichos componentes concretos y universales. Los redujo a seis ingredientes principales, a la vez señalando que no agotan completamente este fenómeno inescrutable en su esencia, sino solo son un intento de dominarlo teóricamente ${ }^{14}$.

La primera categoría que distinguió el filósofo madrileño es el sentido de la vida, su comprensión, que no obstante no tienen carácter intelectual, contemplativo, sino vital. Cuando hablamos de darnos cuenta de la vida no nos referimos, por lo tanto, al nivel de consciencia reflexiva (Selbstbewusstsein), sino a una consciencia irreflexiva, ingenua, que según Ortega no es de hecho una consciencia, sino la propia realidad ${ }^{15}$. Es el llamado yo ejecutivo, que

12 El problema del ser en Ortega analizó en su libro Sara Cameron, El problema del ser en Ortega y Gasset. Buenos Aires: Troquel, 1970, pp. 64.

13 J. Ortega y Gasset, «¿Oué es filosofía?», VIII, p. 365.

14 Véase sobre el tema de las categorías de la vida en Ortega el artículo de A. Marrero, «El constructivismo orteguiano y las categorías de la vida», Asomante, XII (4), (1956), pp. 34-46.

15 Sobre el tema de la conciencia y sobre la superación de su interpretación moderna 
ama a alguien, desea algo, percibe algo, piensa en algo, sin la consciencia de uno mismo que le acompaña. Para que ese yo consciente de sí mismo, ese yo reflexivo pudiera surgir, tendríamos que suspender el yo real y originario que realiza sus actos, es decir, en cierto modo congelarlo o anularlo. Esto también abarcaba una de las acusaciones más importantes de Ortega sobre la fenomenología, que mediante la reducción trascendental y fenomenológica, suspendía lo realmente dado, a saber, la «ejecutividad» y «ponencialidad» de la consciencia, es decir, la realidad de la coexistencia del yo y el mundo, haciendo de la consciencia pura y reflexiva obtenida mediante manipulaciones intelectuales un principio y una conciencia orginaria ${ }^{16}$.

Lo que el fenomenólogo de verdad encuentra - leemos en Prólogo para alemanes - es la «conciencia primaria», «irreflexa», «ingenua», en que el hombre cree lo que piensa, quiere efectivamente y siente un dolor de muelas que duele sin otra reducción posible que la aspirina o la extracción. Lo esencial, pues, de esa «conciencia primaria» es que para ella nada es sólo objeto, sino que todo es realidad. En ella el darse cuenta no tiene un carácter contemplativo, sino que es encontrarse con las cosas mismas, con el mundo ${ }^{17}$.

La segunda categoría es el reconocimiento de la vida como única, intransferible «mía». Ortega la llamaba «unicidad operante» (werktätige Einzigkeit) ${ }^{18}$. Único no significa aquí «uno solo», porque puede existir una cantidad infinita de seres únicos ${ }^{19}$. Dicha singularidad hace al mismo de la vida un área hermenéutica y exclusiva.

Mi vida -como estableció Ortega- por ser única, no puede ser en ninguna de sus partes tuya o de otro. Es, porque única, heterogénea a toda otra cosa y a toda otra vida. Es individuo único de su género en un sentido tan radical que supera

en Ortega escribió Alejandro Martínez Carrasco, La reformulación de la conciencia moderna en Ortega y Gasset, en A. González y $\mathrm{M}^{\mathrm{a}}$ Idoya Zorroza, In umbra intelligentiae. Estudios en homenaje al prof. Juan Cruz Cruz, Navarra: Eunsa, 2011, pp. 571-586.

16 Véase de este tema las reflexiones de Ortega en «La idea de principio en Leibniz. La evolución de la teoría deductiva», IX, p. 1119-1120. Sobre el influjo de la fenomenología en Ortega véase el libro de Javier San Martín, La fenomenología de Ortega, Madrid: Biblioteca Nuenva, 2012, pp. 217. Véase también sobre la modificación de la fenomenología realizada por Ortega en el texto de Jesús Conill, «La transformación de la fenomenología en Ortega y Zubiri», en J. San Martín, Ortega y la fenomenología. Madrid: Uned, 1992, pp. 297-312.

17 J. Ortga y Gasset, «Prólogo para alemanes», IX, p. 156.

18 J. Ortega y Gasset, «Vida como ejecución (el ser ejecutivo). Lecciones Del curso 1929-1930», VIII, p. 198.

19 Ibídem. 
a la unicidad de Dios. Pues ésta no es interna a Dios, sino fundada en razones nuestras. Sólo en tanto en cuanto Dios sea viviente sería verdaderamente único ${ }^{20}$.

La tercera categoría se refiere al ser en el mundo. La vida no es solo yo, sino en igual medida lo que me rodea, el mundo de las cosas y la gente, así como los productos de estos últimos en forma de cultura y civilización. El filósofo madrileño definió todo esto como circunstancia, que son otra parte de mi yo igual de esencial ${ }^{21}$. «Nuestra vida -afirmó- la de cada cual, es el diálogo dinámico entre «yo y sus circunstancia». El mundo es primariamente circunstancia del hombre y sólo „al través de ésta comunica con el universo” $\gg{ }^{22}$. La circunstancia no es, por lo tanto, algo exterior a la vida, sino su ingrediente inmanente. Salvar las propias circunstancia significa aceptarlas, darse cuenta del propio arraigo en ellas. Entonces, de materia dura e insuperable, se convierten en un abanico de posibilidades, en nuestra propia creación, que hace de la vida un área de libertad y decisiones libres del individuo. Es cierto que esta libertad no tiene un carácter absoluto e ilimitado, puesto que la limita precisamente la circunstancia.

La categoría de circunstancia nos introduce al mismo tiempo en la problemática de los dos siguientes componentes de la vida revelados por el filósofo madrileño: la libertad y la fatalidad. Ambos están determinados por una dialéctica mutua, consistente en que la libertad solo puede aparecer en el marco de la necesidad y en relación con ella. En este sentido Ortega escribía que el hombre es «por necesidad libre», lo que significa que no tiene una forma de ser determinada o impuesta de antemano, sino debe crearla en cada instante de su vida, realizarla mediante las acciones y decisiones que toma. Al mismo tiempo, está obligado a elegir lo mejor, donde lo mejor ya no está sujeto a sus elecciones, sino se deriva de lo que Ortega llama el destino. «Vida es, a la vez, fatalidad y libertad, es ser libre dentro de una fatalidad dada. Esta fatalidad nos ofrece un repertorio de posibilidades determinado, inexorable, es decir, nos ofrece diferentes destinos. Nosotros aceptamos la fatalidad y en ella nos decidimos por un destino. Vida es destino» ${ }^{23}$. El filósofo madrileño relacionó el destino con el concepto de vocación. Es la obligación de aspirar a ser uno mismo, a la autenticidad, que no es algo heterónomo respecto a la vida, sino es su imperativo interno. «[...] el verdadero Destino - estableció - es nuestro ser mismo. Lo que fundamentalmente nos pasa es ser el que somos» ${ }^{24}$.

20 Ibídem.

21 Véase de este tema Rodolfo Gutiérrez Simón, «Los límites del sujeto y la libertad en Ortega y Gasset», Daimon, 69, (2016), pp. 109-123.

22 J. Ortega y Gasset, «Prólogo para alemanes», IX, p. 151.

23 J. Ortega y Gasset, «¿Oué es filosofía?», VIII, p. 368.

24 J. Ortega y Gasset, «No ser hombre de partido», IV, p. 308. 
La libertad, que determina nuestra vida, no elimina por lo tanto la necesidad propia de esta vida, sino nos involucra aún más en ella. La vida es un imperativo de ipseidad, es la compulsión de aspirar a hacer realidad y convertir en un hecho lo que solo es un proyecto. Al mismo tiempo, este proyecto no es algo que hayamos elegido libremente, sino algo impuesto. Es una vida que nos impusieron, estrictamente determinada, que cada uno de nosotros debe vivir, tanto si quiere como si no.

Somos nuestro Destino, somos proyecto irremediable de una cierta existencia. En cada instante de la vida notamos si su realidad coincide o no con nuestro proyecto, y todo lo que hacemos lo hacemos para darle cumplimiento. Porque así como ese proyecto que somos no consiste en un plan libérrimamente dibujado por nuestra fantasía, tampoco se halla ahí, como éste, atenido a nuestro buen deseo de cumplirlo o no. Lejos de esto, es un proyecto que por sí mismo se proyecta sobre nuestra vida, que la oprime rigorosamente porque impone su ejecución ${ }^{25}$.

La necesidad, como la otra cara de la libertad, no tiene en Ortega nada que ver con el determinismo tradicional. No es una «necesidad externa, cósmica», que caracteriza, por ejemplo, el caso de los cuerpos celestes, que se mueven por una trayectoria estrictamente determinada, sino una «necesidad interna, vital», una necesidad de actuar y hacer elecciones que en cada instante nos permiten realizar nuestra vocación única e irrepetible.

La necesidad cósmica consiste en que el astro no puede eludir su trayectoria. Pero, en cambio, ésta le es regalada, no tiene que hacérsela él. Su conducta - su ser - le llega ya decidida y, por muy grande que sea y muy ardiente, va el astro, como un niño, dormido en la cuna de diamante de su órbita. El pobre ser humano, por el contrario, se encuentra colocado en una posición dificilísima. Porque es como si se le dijera: «si quieres realmente ser tienes necesariamente que adoptar una muy determinada forma de vida. Ahora: tú puedes, si quieres, no adoptarla y decidir ser otra cosa que lo que tienes que ser. Mas entonces, sábelo, te quedas sin ser nada, porque no puedes ser verdaderamente sino el que tienes que ser, tu auténtico ser». La necesidad humana es el terrible imperativo de autenticidad. Quien libérrimamente no lo cumple, falsifica su vida, la desvive, se suicida. Resulta, pues, que se nos invita a lo que se nos obliga. Se nos deja en libertad de aceptar la necesidad $^{26}$.

25 Ibídem.

26 J. Ortega y Gasset, «Prólogo para alemanes», IX, p. 137. 
La dialéctica de la libertad y la necesidad o fatalidad nos remite finalmente a la sexta y última categoría de vida, que es su temporalidad, o para ser más precisos, su carácter futurista ${ }^{27}$. La vida, entendida como proyecto y tarea, indica que es algo que todavía no existe, algo que se realiza constantemente, algo que se efectúa en el tiempo. El tiempo, que determina nuestra vida, no es sin embargo el mismo tiempo que el tiempo cósmico, el tiempo del mundo natural. Este otro se refiere siempre al presente y no hay sitio en él ni para el pasado ni para el futuro. Al contrario, el tiempo de la vida humana se abre a lo que todavía no ha sucedido y en base a ello descubre lo que hay y lo que hubo. «Nuestra vida es ante todo toparse con el futuro. No es el presente o el pasado lo primero que vivimos, no; la vida es una actividad que se ejecuta hacia adelante, y el presente o el pasado se descubre después, en relación con ese futuro. La vida es futurición, es lo que aún no es» ${ }^{28}$. Así, el pasado y el presente siempre aparecen en la vida, pero solo en relación con el futuro, como elemento que sirve para cumplir el destino, realizar el proyecto de nuestra vida. Esto a su vez hace que el tiempo se convierta en una especie de unidad de todos sus instantes, que se entrelazan en él. «Mi futuro, pues, me hace descubrir mi pasado, para realizarse. El pasado es ahora real porque lo revivo, y cuando encuentro en mi pasado los medios para realizar mi futuro es cuando descubro mi presente. Y todo esto acontece en un instante; en cada instante la vida se dilata en las tres dimensiones del tiempo real interior ${ }^{29}$. El carácter futurista de la vida también hace que tengan prioridad en ella tales actos como el querer, el preferir, el anhelar, el desear. Solo secundariamente entran en juego los actos sensu stricto intelectuales, que sirven ante todo para elaborar métodos que permiten hacer realidad nuestras preferencias. En este sentido, Ortega consideró la razón no una realidad autónoma y originaria, sino la función práctica de la realidad única y auténtica que es la vida humana, la vida de un hombre concreto que se mide con su circunstancia.

\section{LA LIBERTAD Y LA CRÍTICA DE LA INTERPRETACIÓN TRADICIONAL DEL SER HUMANO}

La inscripción de la libertad en el marco de la necesidad y la muestra de la tensión recíproca entre ellas no se podría justificar sin hacer una revisión

27 De este tema véase Sandra Moreno Benítez, «Temporalidad de la vida humana en Ortega», Boletín de la Biblioteca de Menéndez Pelayo, 77 (2001) , pp. 143-150.

28 J. Ortega y Gasset, «Meditación de nuestro tiempo. Introducción al presente», VIII, p. 45 .

29 J. Ortega y Gasset, «Principios de metafísica según la razón vital. Curso de 1932-1933», VIII, p. 699. Véase de este tema Manuel Dieguez Muñoz, Ortega y Gasset. La razón vital y la realidad radical. Palibrio, 2013. 
simultánea del principal problema ontológico: el problema del ser ${ }^{30}$. En esta área, ante todo, había que superar su planteamiento tradicional en el contexto de la pregunta sobre quién es el hombre. «Si yo preguntase con urgencia y rigor al que me lee: ¿quién es usted? - ¿quién es ése a quien al hablar llama usted mismo «yo» y que tiene además un nombre civil? —, la respuesta más próxima sería ésta: yo soy mi cuerpo y mi «alma», psique, conciencia o como se lo quiera denominar ${ }^{31}$. Esta era la interpretación tradicional del ser humano, que buscaba en el hombre su realitas y lo presentaba como un cierto tipo de cosa. Podía ser una cosa física, psíquica, pensante, consciente de sí misma, dotada de alma, pero siempre de algún modo estable y de antemano determinada. El hombre entendido de este modo poseía cierta naturaleza, esencia, sustancia, era «algo que es en sí mismo», donde dicho «es» tenía carácter estático, duradero e invariable. En este sentido, la condición ontológica del hombre no difería de la de una piedra o un triángulo, que se caracterizan por «la identidad, la invariabilidad radical, la estabilidad, la profunda quietud» ${ }^{32}$.

Ortega llamaba a esta interpretación del ser eleatismo e intentaba suprimirla. Para él, considerar al hombre una cosa, ya sea espiritual o física, «es expresar mitos, a lo sumo hipótesis plausibles, pero nada más» ${ }^{33}$. Por eso hay que «aprender a libertarse de la idea tradicional que nos arrastra a hacer consistir siempre la realidad en alguna cosa, sea corporal, o sea mental. El „yo" de que habla el lector en casi todas sus frases, ni es materia ni es espíritu. Es algo previo a todas esas respuestas „teóricas”, es sencillamente el que tiene que vivir una cierta vida» ${ }^{34}$. La vida a su vez tiene carácter dinámico, variable, sucede. No hay nada dado en ella, aparte del propio hecho de la vida. Todos es una tarea para el hombre, incluido su propio ser. Es, como escribía sobre el hombre:

algo radicalmente plástico capaz de ser esto y lo otro y así sin límites. Para hablar del ser del hombre tenemos que inventar un concepto de ser no-eleático, como se ha inventado un espacio no-euclidiano. El hombre es el hombre paleolítico pero también es la Marquise de Pompadour, es Gengis Khan y es Stefan George, es Pericles y es Charles Chaplin. Las formas más dispares del ser pasan por el hombre sin que éste se adscriba a ellas ${ }^{35}$.

30 De este tema véase entre otros el artículo de Rodrigo Grez Toso, «Libertad y condicion humana en Ortega y Gasset», Tiempos Modernos, (1999), pp. 18-19.

31 J. Ortega y Gasset, «No ser hombre de partido», IV, p. 307.

32 J. Ortega y Gasset, «Historia como sistema», VI, p. 61.

33 J. Ortega y Gasset, «No ser hombre de partido», IV, p. 307.

34 Ibídem.

35 J. Ortega y Gasset, «Aurora de la razón histórica», V, p. 375. 
Este carácter de la vida dialéctico, variado, que se realiza, requiere a su vez la elaboración de una lógica diferente a la tradicional. No puede ser una lógica basada en el principio de la no contradicción y la identidad. En efecto, la vida al mismo tiempo es y no es, es esto y lo otro, y todo se produce en ella en un continuo movimiento y suceso. Por este motivo Ortega empleó, como antes Hegel, la filosofía heraclitiana del devenir del ser, haciendo de ella la base de una nueva lógica: la lógica de la razón vital. «El hombre - estableció - no es, sino que «va siendo» esto y lo otro ...(...)... Ese ,ir siendo" es lo que, sin absurdo, llamamos ,vivir”. No digamos, pues, que el hombre es, sino que vive» ${ }^{36}$. El método de esta lógica es la dialéctica, pero no la de Hegel, que Ortega definió como «muy pobre», porque ésta lleva en movimiento las ideas mecánicamente de contradicción a contradicción, sino la dialéctica real, es decir, la que se deriva del objeto pensado por nosotros, no del propio pensamiento $^{37}$. La vida es dialéctica, porque es un todo móvil que deviene, y pensar en una idea, un elemento, una cuestión nos lleva inevitablemente a pensar en otra. Todo en la vida aparece relacionado y esta necesidad de relación, de síntesis que muestra nuestro pensamiento tiene su fuente en la realidad, no en el sujeto racional que piensa en ella, como querían Kant y los racionalistas.

Igualmente se presenta la cuestión de la libertad. Tampoco ella aparece aislada, porque es un problema de la propia vida. Por eso debemos observar las diferentes emanaciones de la libertad, que aparecen en diversos planos, en la política, el arte, la ciencia, etc., en el contexto de toda la vida humana, porque ella es la única realidad radical. Podemos citar aquí como ejemplo la crítica orteguiana del liberalismo tradicional o abstracto, basado en la exclusividad de la libertad y el lema «La libertad ante todo». «¿La libertad ante todo?preguntó Ortega - Yo no la deseo, porque con ella sola no se hace nada. La libertad con todo» ${ }^{38}$. En otro lugar escribió: "La libertad es una cosa que no se puede querer sola, como no se puede querer solo el perfil de una mujer sin la carne que lo sostiene» ${ }^{39}$.

En resumen, en opinión de Ortega la interpretación del hombre no como aquel que es, sino aquel que deviene, que vive, es la única que justifica y

36 J. Ortega y Gasset, «Historia como sistema y del Imperio Romano», VI, p. 71.

37 J. Ortega y Gasset, «¿Qué es la ciencia, qué la filosofia?», VIII, p. 166.

38 J. Ortega y Gasset, «Vaguedades», III, p. 791.

39 Ibídem, p. 797. Sobre el tema de la libertad en en ámbito político de la filosofía de Ortega véase Héctor Pinto Benavides, «La „libertad política” en Ortega y Gasset. Una aproximación a su pensamiento metapolítico», Mutatis Mutandis: Revista Internacional de Filosofia, 3, (2014), pp. 115-131. 
fundamenta metafísicamente la existencia de la libertad ${ }^{40}$. En efecto, si el hombre fuera algo estable, dotado de una esencia dada de antemano, no podría intervenir de ningún modo en su ser, no podría decidir sobre sí mismo, porque sus decisiones no cambiarían nada en su ser. La libertad real, no abstracta ni hipotética, implica por lo tanto un ser privado de esencia, un ser plástico, dotado de imaginación, que le permite proyectarse a sí mismo de manera libre, pero no de cualquier manera. No podemos formar nuestra vida de cualquier manera, porque estamos inscritos en el horizonte de nuestra circunstancia, en la necesidad de la que es emanación. No elegimos el mundo en el que vivimos, igual que no elegimos nuestro cuerpo, personalidad, familia, época histórica o cultura. No obstante, nos queda cierto abanico de posibilidades, entre las que podemos elegir lo que, en nuestra opinión, es en un momento lo mejor, lo que hace que devengamos más nosotros mismos, que nos convirtamos en quienes auténticamente somos. Por supuesto, parece razonable formular aquí una pregunta: ¿hasta dónde podemos estar seguros que elegimos lo mejor y que nuestra existencia es precisamente la auténtica? Según Ortega, esto no es un problema, porque esta dirección nos la indica la propia vida, que se impone al hombre como la necesidad de cumplir un destino concreto y estrictamente determinado. De ello se deduce que, si no sentimos en nuestra vida una disonancia entre quienes somos en un momento dado y quienes deberíamos ser (no hay que confundirlo con quienes querríamos ser), seguimos el camino correcto de la autorrealización y vivimos y creamos de un modo auténtico nuestro proyecto - el proyecto que es para cada uno de nosotros nuestra propia vida, única e intransferible.

\section{REFERENCIAS BIBLIOGRÁFICAS}

CAMERON, S. 1970: El problema del ser en Ortega y Gasset. Buenos Aires: Troquel. CONILL, J. 1992: «La transformación de la fenomenología en Ortega y Zubiri», en J. San Martín (eds), Ortega y la fenomenología. Madrid: Uned, pp. 297-312.

DIEGUEZ MUÑOZ, M. 2013: Ortega y Gasset. La Razon Vital y La Realidad Radical. Bloomington: Palibrio.

FERREIRO LAVEDÁN M. I. 2002: «Ortega y Gasset, iniciador del pensamiento complejo», Revista de Estudios Orteguianos, 4, pp.137-154

GONZÁLEZ SANDOVAL BUEDO J. 2001: «El concepto de „superación” en Ortega», Contrastes, 6, p. 183.

GREZ TOSO R. 1999: «Libertad y condicion humana en Ortega y Gasset», Tiempos Modernos, pp. 18-19.

40 Sobre este tema véase el artículo de Mijail Malishev, Julián Herrera González, «José Ortega y Gasset: La metafísica existencial de la vida», Eidos, 12, (2010), pp. 214-235. 
GUTIÉRREZ SIMÓN, R. 2016:, «Los límites del sujeto y la libertad en Ortega y Gasset», Daimon, 69, pp. 109-123.

HARTMANN N. 1936: «Der philosophische Gedanke und seine Geschichte», en Abhandlungen der Preußischen Akademie der Wißenschaften, PhilosophischHistorische Klaße. 1936.

HARTMANN N. 1964: Der Aufbau der realen Welt. Grundriss der allgemeinen Kategorienlehre. Aufl. 3. Berlín: De Gruyter.

LESZCZYNA D. (2020: Del idealismo al realismo crítico. La política como realización en José Ortega y Gasset. Berlín, Bern, Bruxelles, New York, Oxford, Warszawa, Wien: Peter Lang.

MALISHEV, M., HERRERA GONZÁLEZ, J. 2010: «José Ortega y Gasset: La metafísica existencial de la vida», Eidos, 12, pp. 214-235.

MARRERO, A. 1956: «El constructivismo orteguiano y las categorías de la vida», Asomante, XII (4), pp. 34-46.

MARTÍNEZ CARRASCO, A. 2011: «La reformulación de la conciencia moderna en Ortega y Gasset», en A. González y M $\mathrm{M}^{\mathrm{a}}$ Idoya Zorroza, In umbra intelligentiae. Estudios en homenaje al prof. Juan Cruz Cruz, Navarra: Eunsa, pp. 571-586.

MORENO BENÍTEZ, S. 2001: «Temporalidad de la vida humana en Ortega», Boletín de la Biblioteca de Menéndez Pelayo, 77, pp. 143-150.

ORRINGER, N. R. 2019: «Reforma de la filosofía de Ortega y la nueva filosofía de la vida de Dilthey según Misch», Disputatio, 11, p. 116-117.

ORTEGA Y GASSET, J. 2004-2010: Obras completas t. I-X, Fundación José Ortega y Gasset/Centro de Estudios Orteguianos (eds.), Madrid: Fundación José Ortega y Gasset \& Taurus.

ORTEGA Y GASSET, J. 2007: Hegel. Notas de trabajo. D. Hernández Sánchez (eds.), Madrid: Abada.

PINTO BENAVIDES, H, 2014: «La libertad política” en Ortega y Gasset. Una aproximación a su pensamiento metapolítico», Mutatis Mutandis: Revista Internacional de Filosofía, 3, pp. 115-131.

SAN MARTÍN, J. 2012: La fenomenología de Ortega, Madrid: Biblioteca Nueva.

DOROTA LESZCZYNA es Profesora de Filosofía en la Universidad de Wroclaw de Polonia

Líneas de Investigación:

Filosofía española del siglo XIX y XX, Filosofía trascendental, filosofía de la vida

Publicaciones recientes:

(2020): Ortega y la escuela de Marburo. Berlin, Bern, Bruxelles, New York, Oxford, Warszawa, Wien: Peter Lang. 
(2020): Del idealismo al realismo crítico. La política como realización en José Ortega y Gasset. Berlín, Bern, Bruxelles, New York, Oxford, Warszzawa, Wien: Peter Lang.

Correo electrónico: dorota.leszczyna@uwr.edu.pl 
